\title{
Review Paper: Genetic Basis of Congenital Myasthenic Syndrome: A Review Study
}

\author{
Pouria Mohammadi ${ }^{1}$, Seyed Mohammad Salar Zaheryani ${ }^{2^{*}}$ (D)
}

1. Research Center for Molecular Medicine, Hamadan University of Medical Sciences, Hamadan, Iran. 2. Poostchi Eye Research Center, Shiraz University of Medical Sciences, Shiraz, Iran.

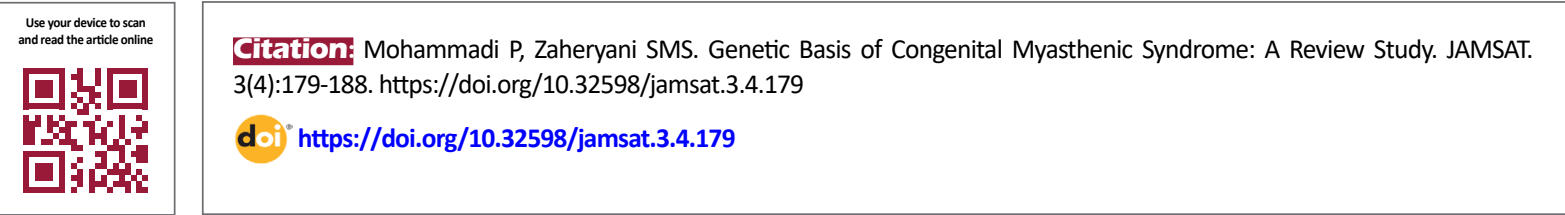

Article info:

Received: 26 Jan 2017

Accepted: 18 May 2017

Keywords:

Congenital myasthenic syndromes, Synaptic transmission, Mutation, Neuromuscular junction, Ophthalmoplegia

\begin{abstract}
The neuromuscular junction is a highly specialized cholinergic synapse, essential for initiating nerve-evoked muscle contractions by means of neuromuscular transmission. Loss or dysfunction of any component of this junction might affect synaptic performance. Congenital Myasthenic Syndromes (CMSs) are rare heterogeneous disorders of autosomal inheritance caused by genetic defects affecting neuromuscular transmission that results in skeletal muscle weakness and abnormal fatigability on exertion. The onset is usually from birth to childhood. CMSs are more uncommon than autoimmune myasthenia gravis. CMSs are classified based on their genetic and clinical presentations into presynaptic, synaptic basal lamina, and postsynaptic CMSs. To date, mutations in more than 25 genes have been implicated in the pathogenesis of CMSs. In this review article, different CMSs diagnostic procedures are investigated, and the genetic, clinical, and molecular aspects of CMSs are outlined.
\end{abstract}

\section{Clinical Characteristics}

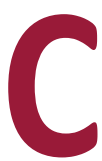

ongenital Myasthenic Syndromes (CMSs) represent a clinical and genetic heterogeneous group of rare inherited conditions characterized by fatigable muscle weakness, including ocular, bulbar and limb muscles, caused by a defective neuromuscular transmission, which worsens with physical exertion. Different CMS subtypes vary with respect to its severity, the age of onset, course of weakness, and response to treatment [1]. The muscle weakness in most patients occur within the first 2 years of life, but it can also appear in adolescence or adulthood. Main features of the infantonset subtype include feeding difficulties; poor sucking and weak crying, respiratory insufficiency with sudden apnea and cyanosis, choking spells, blepharoptosis, as well as facial and bulbar weakness. Subtypes with childhood-onset are presented with atypical muscle fatigability, difficulties in activities like climbing stairs, late motor milestones, transient eyelid ptosis, and constant or transient extraocular muscle weakness [2].

\section{Epidemiology}

Estimating the prevalence of CMS is difficult because they are rare and have variable expressions in general population, besides patients have not been diagnosed genetically yet. Recently a study in the United Kingdom illustrated that prevalence of CMS in under 18 years old

* Corresponding Author:

Seyed Mohammad Salar Zaheryani, MD

Address: Poostchi Eye Research Center, Shiraz University of Medical Sciences, Shiraz, Iran.

Tel: +98 (912) 5243315

E-mail: smszaheryany@gmail.com 
individuals was about 9.2 cases per million. A significant part of the patients who diagnosed according to clinical presentations have not been verified genetically yet. Therefore, prevalence of this disorder might increase in the future [3].

\section{Diagnosis}

\section{Generic diagnosis}

Congenital myasthenic syndromes can be diagnosed based on clinical features such as fatigable weakness involving ocular, bulbar, and limb muscles with the onset at birth or during early childhood, as well as decremental EMG response of CMAP (the compound muscle action potential) on low-frequency $(2-3 \mathrm{~Hz})$ stimulation. In sporadic cases after age one, tests for antibodies including anti-AChR and anti-MUSK are indicated. In newborn child poor sucking or weak crying, generalized hypotonia, or arthrogryposis are the only features, so CMS diagnosis might be hard in them $[4,5]$.

\section{Genetic diagnosis}

The genetic diagnosis may verify primary diagnose of CMS. Whole genome and exome sequencing are being used to find CMS mutations but these methods and bioinformatics analysis are costly and mutations must be identified by Sanger sequencing and gene panels for CMS mutations that are now commercially available. Thus copy number mutations can be verified by array methods such as comparative genomic hybridization (CGH array) [6].

\section{Classification and Genetic Changes}

Congenital Myasthenic Syndromes (CMSs) are classified based on the pattern of inheritance. These disorders are commonly inherited in an autosomal recessive pattern. Rarely, they are inherited in an autosomal dominant fashion (Table 1). CMSs are also classified according to the localization of the corresponding deficiency at the neuromuscular junction as presynaptic, synaptic basal lamina-associated, and postsynaptic compartment CMSs [2, 4]. So far, mutations in more than 25 genes is influential in the Neuromuscular Junction (NMJ) and have been identified in causing CMSs. Gene mutations change the function of the neuromuscular junction proteins and defect signal transmission between the ends of nerve cells and muscle cells. Defective signaling results in an impaired movement of skeletal muscles, fatigable muscle weakness, and delayed development of motor skills [1].

\section{Presynaptic CMSs}

\section{Dysfunction of choline acetyltransferase (Encoded by} the CHAT gene, 10q11.23)

Neuromuscular transmission between cholinergic neurons and their target cells is dependent on functional choline acetyltransferase (ChAT) [7]. ChAT deficiency is a type of CMSs caused by a defected enzyme located in the presynaptic terminal region of the neuron. CHAT mutation is also referred to as CMSs associated with threatening episodic apnea and early onset in the neonatal period. Various degrees of ptosis are also reported $[7,8]$. Anticholinesterase medication, such as pyridostigmine might be effective and some patients with CHAT mutations might be partially responsive to combined treatment with an anticholinesterase drugs and amifampridine (3,4-diaminopyridine) [9].

Synaptotagmin 2 dysfunction (Encoded by the SYT2 gene 1q32.1 (and Lambert Eaton Myasthenia Syndrome

Synaptotagmin 2 (SYT2), a synaptic vesicle protein, is the main isoform of the synaptotagmin family at mammalian neuromuscular junctions, which acts as a calcium sensor for signal transmission. Autosomal dominant heterozygous missense mutations in the $C 2 B$ domain is a major cause of presynaptic congenital myasthenic syndromes and hereditary Lambert Eaton Myasthenic Syndrome (LEMS) [10]. LEMS is a rare presynaptic disease of neuromuscular transmission due to inappropriate secretion of acetylcholine. Clinical features are lower tendon reflexes, proximal muscle weakness, au tonomic manifestations, and post-tetanic potentiation. These primary representations can be analogous to that

Table 1. Patterns of inheritance

\section{Pattern}


of Myasthenia Gravis (MG), but their progressions show some significant distinctions [11].

Synaptosomal dysfunction associated protein 25KD (Encoded by the SNAP25 gene, 20p12.2)

SNAP25 belongs to SNARE (soluble N-ethylmaleimide sensitive factor attachment protein receptors) complex. [12]. Synaptobrevin and syntaxin 1 help to produce SNARE complex by providing one $\alpha$-helix. SNAP- 25 combined with synaptobrevin and syntaxin 1 and the chosen binding of these proteins allow vesicle fusion to occur at the true site. Autosomal dominant mutations of SNAP25b is presented with muscle weakness and ptosis. This results from the decline in the amount of acetylcholine secreted from the presynaptic nerve terminal following each impulse [13]. Amifampridine (3,4-diaminopyridine) is often used in the treatment of SNAP25 congenital myasthenic syndromes [2].

Unconventional myosin IXA dysfunction (Encoded by the MYO9A gene, 15q23)

Unconventional myosins are expressed in neurons of the peripheral nervous system that establish a branch of myosin family of molecular motors. They attach to actin filaments and move relative to the actin cytoskeleton of cells [14]. By identifying the compound heterozygous and homozygous recessive missense variants in an unconventional myosin gene, MYO9A in two unrelated congenital myasthenic syndrome families represent CMSs. While, mutations in MYO5A are not fully categorized in the presynaptic form, the manifestations and the experimental data are consistent with a presynaptic dysfunction [15-17].

\section{Synaptic CMSs}

Mutations in acetylcholinesterase-associated collagen (Encoded by COLQ gene 3p25.1)

Acetylcholinesterase deficiency results from mutations in the Collagen-Like tail subunit (COLQ) that encodes the collagenous tail of Acetylcholinesterase (AChE) $[18,19]$. COLQ gene mutations are generally explained in synaptic CMSs patients suffering from a severe, progressive weakness with the onset at birth or in early childhood. Hypotonia, ophthalmoparesis, ptosis, poor cry and suck and restrictive respiratory conditions are the symptoms in the neonatal period. In addition, patients with the late onset, have a milder course of the disorder. Mutations are mainly autosomal recessive and mostly act in compound heterozygosity way $[20,21]$.
Anti-acetylcholinesterase therapy, such as pyridostig mine and amifampridine, which are beneficial for other forms of CMSs, exacerbates the clinical course in cases of AChE deficiency. Treatment with ephedrine and albuterol has been effective in some cases $[22,23]$.

Dysfunction of Laminin- $\beta 2$ (encoded by the LAMB2 gene 3p21.31) causing a severe form of synaptic congenital myasthenic syndrome and Pierson syndrome

Laminin proteins are thought to be involved in nuclear consistency, chromatin structure, and gene expression [24]. Mutations in the gene LAMB2 represents a new type of synaptic CMSs that shows a wide variety of phenotypes with classic renal and ocular dysfunction of Pierson myasthenic syndrome, a severe type of (CMSs) with autosomal recessive inheritance pattern related to congenital nephrosis and ocular defects. This emphasizes the basic role of laminin- $\beta 2$ in the evolution of the human Neuromuscular Junction (NMJ). It represents a pyridostigmine avoidance (clinical worsen) and ephedrine responsive phenotype form of CMSs with prominent proximal limb fatigue [24, 25].

\section{Postsynaptic CMSs}

Primary defects of acetylcholine receptor

Congenital myasthenic syndromes with primary acetylcholine receptor defect (with absent or only partial kinetic anomalies) shows the most common form of CMSs and associated with mutations in genes that encode any of the acetylcholine receptor subunits, including CHRNA1, CHRNB, CHRND, CHRNE, CHRNG. Mutations in CHRNE are one of the most common causes for their defects in both alleles of CHRNA1, CHRNB or CHRND genes that are often not compatible with life, resulting in fetal period abortion [26-28]. There is partial responsive pattern to pyridostigmine, amifampridine (3,4-diaminopyridine) and albuterol use in clinical practice [2].

\section{Slow channel congenital myasthenic syndromes}

The slow channel CMSs are involved in mutations of Acetylcholine Receptor (AChR) subunit-genes that present autosomal dominant inheritance [29]. Muscle weakness and severity of disease phenotype varies, and might manifest during neonatal period or might not develop until maturity. Scapular, cervical and finger contraction muscles are often exclusively involved. Uncommon late-onset manifestations have been identified as imitating autoimmune myasthenia gravis and scarcely 
with mildly raised serum creatine kinase rates [30]. The patients are responsive to fluoxetine and quinidine, but unresponsive to amifampridine (3,4-diaminopyridine) and pyridostigmine [2].

\section{Fast channel congenital myasthenic syndromes}

Identified mutations affecting $A, D$ and $E$ subunits of AChR cause fast channel type of congenital myasthenic syndrome. Pattern inheritance of fast channel syndrome is autosomal recessive and clinical severity varies that usually starts within the first 10 years of life. The phenotypes of fast channel syndrome include ocular, bulbar, and respiratory symptoms and extreme limb weakness [31, 32]. The patients are responsive to the combination of amifampridine (3,4-diaminopyridine) and cholinesterase inhibitors, however, fluoxetine and quinidine must be avoided [2]

Dysfunction of plectin (Encoded by the PLEC gene 8q24.3)

Plectin is a cytolinker protein with exon 1 splice variants causing multiple isoforms, with critical tasks in signal pathway, cytoskeleton stability, and keeping the integrity of cell and whole tissue [33]. Pathogenic mutations in plectin cause Epidermolysis Bullosa Simplex (EBS), Muscular Dystrophy (MD), pyloric atresia, limbgirdle muscular dystrophy type $2 \mathrm{Q}$, and congenital myasthenic syndromes. Patients with EBS since infancy develop a progressive myopathy and congenital myasthenic syndrome refractory to pyridostigmine [34, 35]

Prolyl endopeptidase-like protein dysfunction (Encoded by the PREPL gene 2p21)

In patients with hypotonia-cystinuria syndrome, a recessive congenital disorder, microdeletion of the SLC3A1 and PREPL genes on chromosome 2p21 is presented with hypotonia at birth, nephrolithiasis, deficiency of growth hormone, minor facial dysmorphism, and thrive failure [36]. Mutations in PREPL gene is a novel monogenic disorder that causes a congenital myasthenic syndrome with presynaptic and postsynaptic manifestations. The congenital myasthenic syndrome in PREPL deficiency with or without cystinuria might respond to pyridostigmine during childhood [37].

Rapsyn dysfunction (Encoded by RAPSN gene 11p11.2)

RAPSN mutations are accountable for Rapsyn (RAPSN) and AChR reduction at the neuromuscular junction [38]. Pathogenic mutations in RAPSN are a common cause of postsynaptic congenital myasthenic syndromes that lead to a phenotype specified by bulbar symptoms, neck muscle fatigue, oscillating ptosis and moderate proximal muscle weakness. These autosomal recessive CMSs are presented most frequently in neonates during the first year of life, imitating chronic hypoxic ischemia. Clinical findings associated with neuromuscular junction deficiency symptoms might raise the probability of rapsyn dysfunction $[39,40]$. Amifampridine (3,4-diaminopyridine) and salbutamol are often used to treat rapsyn CMSs [4].

Sodium channels dysfunction (NaV1.4) (Encoded by the SCN4A gene 17q23.3)

Over 60 mutations of SCN4A have been detected in patients with myotonia, periodic paralysis and CMSs [41]. Most mutations are missense with gain-of-function deficiencies that increase susceptibility to myotonia or periodic paralysis. Loss-of-function is rare and related to an extremely rare form of CMS with brief and sudden attacks of muscle weakness and neonatal respiratory failure, while a blend of loss and gain of function mutations is associated with hypokalemic periodic paralysis [42]. Treatment with acetazolamide and pyridostigmine has been effective in some cases [43].

Defects in endplate development and maintenance CMSs

Agrin dysfunction (Encoded by AGRN gene 1p36.33)

Agrin is a heparan sulfate proteoglycan, which plays an important function in the evolution and retention of the neuromuscular junction. Agrin forms agrin-MUSK-LRP4 DOK7 signaling pathway together with DOK7, LRP4, and MUSK [44]. Autosomal recessive mutations in the AGRN gene were shown to cause a very uncommon spectrum of congenital myasthenic syndromes with ptosis and fatigable limb weakness. They also show an unusual correlation between the mutated gene and the related phenotype. It provides a proper rationale to diagnose patients with obvious distal myopathy for a neuromuscular deficiency and agrin-related mutations [45]. Salbutamol and ephedrine treatment is recommended for patients with mutations in the agrin-LRP4-MUSK-DOK7 pathway and general failure in response to amifampridine (3,4-diaminopyridine) and pyridostigmine [2].

\section{Receptor tyrosine kinase (MUSK) dysfunction (Encoded} by the MUSK gene 9q31.3)

Mutations in MUSK result in extremely rare CMSs. The phenotype explains a more intense clinical feature with prenatal onset, or during infancy. Predominant bulbar and respiratory defect with neonatal ptosis, facial and 
Table 2. Classification of congenital myasthenic syndromes related to molecular targets at the neuromuscular junction

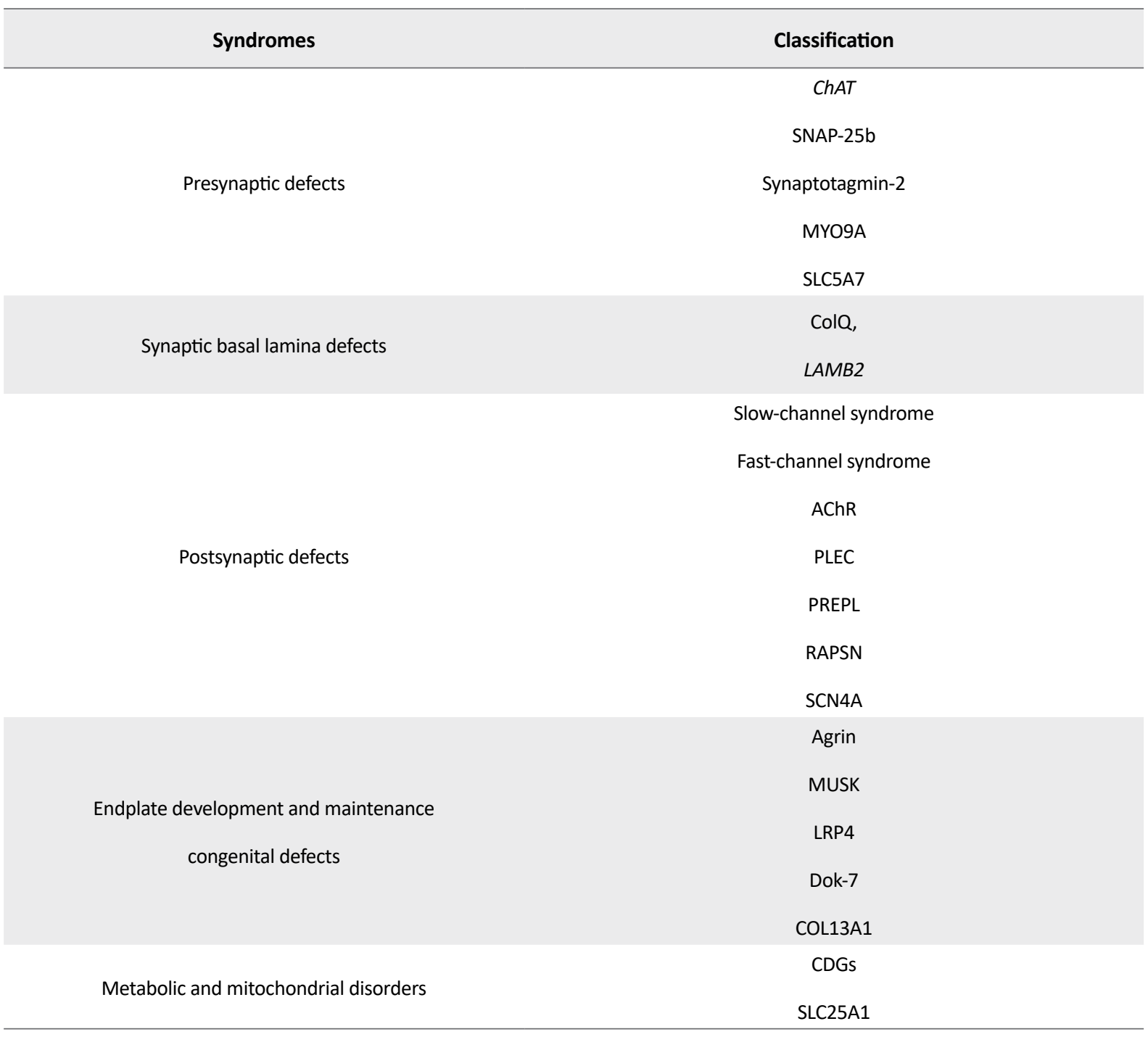

JAMSAT

axial weakness, and ophthalmoparesis are of diagnostic issues [46]. Amifampridine (3,4-diaminopyridine) is often used to treat MUSK CMS, and pyridostigmineavoidance phenotype (clinically worsen) $[2,47]$.

Low-density lipoprotein receptor-related protein 4 dysfunction (Encoded by the LRP4 gene, 11p11.2)

LRP4 expressed on the surface of the neuromuscular junction postsynaptic membrane is a receptor for neurally-released agrin, and LRP4 bound by agrin activates MUSK [48]. Activated MUSK with Dok7 stimulates rapsyn to localize and anchor AChR on the postsynaptic membrane that cooperates with other proteins in neuromuscular junction collection and maintenance. LRP4 mutations cause diseases, including Congenital Myas- thenic Syndrome (CMSs), Cenani-Lenz syndactyly syndrome, and sclerosteosis [49].

Cytoplasmic protein downstream of kinase 7 dysfunction (Encoded by the DOK7 gene 4p16.3)

Autosomal recessive mutations in DOK7 gene are responsible for approximately $10 \%$ of the genetically identified CMSs, and limb-girdle type of CMSs. This gene is essential not only for the organization, but also for the maintenance of neuromuscular junctions [50]. The clinical feature of CMSs with DOK7 mutations varies and differs significantly from CMSs caused by mutations in other genes. The age of onset might differ from neonates to the third decade of life. However, most patients manifest a specific 'limb-girdle' weakness with frequent respiratory problems and ptosis, but without ophthal- 
moparesis [51]. Obtaining CMSs genetic diagnosis is essential because of various kinds of treatment, associated with the mutant gene. Patients do not benefit from acetylcholinesterase inhibitors and clinical worsening is common after pyridostigmine use, but clinical improvement has been frequently observed after using ephedrine, salbutamol, and albuterol [52].

Collagen type XIII alpha1 chain dysfunction (Encoded by the COL13A1 gene 10q22.1)

COL13A1 is a large gene (157 kb in size and at least 38 exons) that encodes the alpha chain of atypical, non-fibrillary transmembrane collagens and expressed at low levels in connective tissues. COL13A1 is present in the postsynaptic and synaptic basement membrane and involved in the development and maturation of the neuromuscular junction, which has been purposed as a potential congenital myasthenia syndrome-related protein [53]. Very early-onset of CMSs with the autosomal recessive pattern of inheritance has been recently explained by mutations in the COL13A1 gene. Its clinical manifestation varies that consists of proximal and distal limb hypotonia, ptosis, feeding dysfunction, infant-onset spinal rigidity, respiratory deficiency, dyspnea on exertion with exercise intolerance, dysphagia, gastroesophageal reflux, and poor head control [54]. Salbutamol and amifampridine (3,4-diaminopyridine) treatment is recommended in patients with mutations in the COL13A1 gene [2].

Genes encoding proteins involved in glycosylation mutations

Disorders in glycosylation are associated with distinctive neuromuscular syndromes, including congenital myasthenic syndromes by mutations in genes encoding the enzymes DPAGT1 (11q23.3), GFPT1 (2p13.3), ALG2 (9q22.33), ALG14 (1p21.3), and GMPPB (3p21.31) [55]. Mutations in GFPT1 gene exhibit less than $3 \%$ of all CMSs. They are presented as slowly progressive muscle fatigue with limb-girdle muscular dystrophy (LGMD)-like phenotype responsive to pyridostigmine. Some variants showed severe dysphagia, myopathy, ptosis, and respiratory dysfunctions, which are rarely detected [56, 57]. The clinical manifestations of mutations in DPAGT1 gene are mild to severe muscle weakness, intellectual defects, unresponsiveness to pyridostigmine and amifampridine, and partial responsiveness to salbutamol $[58,59]$. Both syndromes arising from ALG2 and ALG14 genes mutations with an early-onset LGMD-like CMSs, starting in the childhood and manifest as a limb-girdle pattern of muscle weakness with deficiencies in both neuromuscular junction and sarcomere. Treatment with pyridostigmine might benefit some patients [60]. GMPPB congenital myasthenic syndrome patients display clinical presentations characteristic of congenital myasthenic syndrome types, due to glycosylation dysfunction with various weaknesses in proximal limbs, while eye and facial muscles are mainly spared. Although clinical features of GMPPB-related CMSs might be complicated by the appearance of myopathic manifestations, the correct diagnosis is significant due to possible response to proper treatments [61].

\section{Conclusion}

CMSs are rare, hereditary, heterogeneous group of disorders, associated with genetic dysfunction of neuromuscular junction proteins. Clinical presentations of this disease are similar to myasthenia gravis, but CMSs are not autoimmune. Diagnosing CMS because of a large number of affected genes with various presentations and absence of a family history is very difficult; therefore, its treatment requires knowledge of the mutated gene. In this article, we attempted to review the relevant genes and mutations. Table 2 reviews the classification of CMS related to molecular targets at the neuromuscular junction. In addition, the symptoms and latest therapeutic advancements were noted.

\section{Ethical Considerations}

\section{Compliance with ethical guidelines}

The authors adhered to the declaration of Helsinki, ethics in research.

\section{Funding}

This research received no specific grant from any funding agency in the public, commercial, or not-for-profit sectors.

\section{Conflict of interest}

The authors declared no conflicts of interest.

\section{Acknowledgments}

The authors wish to thank the staff of Research Center for Molecular Medicine, Hamadan University of Medical Sciences, Hamadan, Iran. The authors also appreciate Mr. H. Argasi at the Research Consultation Center (RCC) of Shiraz University of Medical Sciences for his invaluable assistance in editing this manuscript. 


\section{References}

[1] Hantaï D, Richard P, Koenig J, Eymard B. Congenital myasthenic syndromes. Current Opinion in Neurology. 2004; 17(5):539-51. [DOI:10.1097/00019052-200410000-00004] [PMID]

[2] Souza PVSd, Batistella GNdR, Lino VC, Pinto WBVdR, Annes M, Oliveira ASB. Clinical and genetic basis of congenital myasthenic syndromes. Arquivos de Neuro-Psiquiatria. 2016; 74(9):750-60. [DOI:10.1590/0004-282X20160106] [PMID]

[3] Rodriguez Cruz PM, Palace J, Beeson D. Congenital myasthenic syndromes and the neuromuscular junction. Current Opinion in Neurology. 2014; 27(5):566-75. [DOI:10.1097/ WCO.0000000000000134] [PMID]

[4] Engel AG. Current status of the congenital myasthenic syndromes. Neuromuscular Disorders. 2012; 22(2):99-111. [DOI:10.1016/j. nmd.2011.10.009] [PMID] [PMCID]

[5] McMacken G, Abicht A, Evangelista T, Spendiff S, Lochmuller H. The increasing genetic and phenotypical diversity of congenital myasthenic syndromes. Neuropediatrics. 2017; 48(4):294-308. [DOI:10.1055/s-0037-1602832] [PMID]

[6] Engel AG, Shen X-M, Selcen D, Sine SM. Congenital myasthenic syndromes: Pathogenesis, diagnosis, and treatment. The Lancet Neurology. 2015; 14(4):420-34. [DOI:10.1016/S14744422(14)70201-7]

[7] Arredondo J, Lara M, Gospe SM, Mazia CG, Vaccarezza M, GarciaErro $M$, et al. Choline acetyltransferase mutations causing congenital myasthenic syndrome: Molecular findings and genotypephenotype correlations. Human Mutation. 2015; 36(9):881-93. [DOI:10.1002/humu.22823] [PMID] [PMCID]

[8] Kraner S, Laufenberg I, Straßburg HM, Sieb JP, Steinlein OK. Congenital myasthenic syndrome with episodic apnea in patients homozygous for a CHAT missense mutation. Archives of Neurology. 2003; 60(5):761-3. [DOI:10.1001/archneur.60.5.761] [PMID]

[9] Ohno K, Tsujino A, Brengman JM, Harper CM, Bajzer Z, Udd B, et al. Choline acetyltransferase mutations cause myasthenic syndrome associated with episodic apnea in humans. Proceedings of the National Academy of Sciences. 2001; 98(4):2017-22. [DOI:10.1073/pnas.98.4.2017] [PMID] [PMCID]

[10] Herrmann DN, Horvath R, Sowden JE, Gonzales M, SanchezMejias A, Guan Z, et al. Synaptotagmin 2 mutations cause an autosomal-dominant form of lambert-eaton myasthenic syndrome and nonprogressive motor neuropathy. The American Journal of Human Genetics. 2014; 95(3):332-9. [DOI:10.1016/j. ajhg.2014.08.007] [PMID] [PMCID]

[11] Baker K, Gordon SL, Grozeva D, van Kogelenberg M, Roberts NY, Pike $M$, et al. Identification of a human synaptotagmin-1 mutation that perturbs synaptic vesicle cycling. The Journal of Clinical Investigation. 2015; 125(4):1670-8. [DOI:10.1172/JCl79765]

[12] Shen XM, Selcen D, Brengman J, Engel AG. Mutant SNAP25B causes myasthenia, cortical hyperexcitability, ataxia, and intellectual disability. Neurology. 2014; 83(24):2247-55. [DOI:10.1212] WNL.0000000000001079] [PMID] [PMCID]

[13] Mohrmann R, de Wit H, Connell E, Pinheiro PS, Leese C, Bruns $D$, et al. Synaptotagmin interaction with SNAP-25 governs vesicle docking, priming, and fusion triggering. Journal of Neuroscience. 2013; 33(36):14417-30. [DOI:10.1523/JNEUROSCI.1236-13.2013] [PMID] [PMCID]
[14] Omelchenko T, Hall A. Myosin-IXA regulates collective epithelial cell migration by targeting RhoGAP activity to cell-cell junctions. Current Biology. 2012; 22(4):278-88. [DOI:10.1016/j. cub.2012.01.014] [PMID] [PMCID]

[15] O'Connor E, Töpf A, Müller JS, Cox D, Evangelista T, Colomer J, et al. Identification of mutations in the MYO9A gene in patients with congenital myasthenic syndrome. Brain. 2016; 139(8):214353. [DOI:10.1093/brain/aww130] [PMID] [PMCID]

[16] Barwick Katy E, Wright J, Al-Turki S, McEntagart Meriel M, Nair A, Chioza B, et al. Defective presynaptic choline transport underlies hereditary motor neuropathy. American Journal of Human Genetics. 2012; 91(6):1103-7. [DOI:10.1016/j.ajhg.2012.09.019] [PMID] [PMCID]

[17] Bauché S, O'Regan S, Azuma Y, Laffargue F, McMacken G, Sternberg $D$, et al. Impaired presynaptic high-affinity choline transporter causes a congenital myasthenic syndrome with episodic apnea. The American Journal of Human Genetics. 2016; 99(3):753-61. [DOI:10.1016/j.ajhg.2016.06.033] [PMID] [PMCID]

[18] Ohno K, Brengman J, Tsujino A, Engel AG. Human endplate acetylcholinesterase deficiency caused by mutations in the Collagen-Like tail subunit (ColQ) of the asymmetric enzyme. Proceedings of the National Academy of Sciences. 1998; 95(16):9654-9. [DOI:10.1073/pnas.95.16.9654]

[19] Donger C, Krejci E, Serradell AP, Eymard B, Bon S, Nicole S, et al. Mutation in the human acetylcholinesterase-associated collagen gene, $C O L Q$, is responsible for congenital myasthenic syndrome with end-plate acetylcholinesterase deficiency (Type Ic). The American Journal of Human Genetics. 1998; 63(4):967-75. [DOI:10.1086/302059] [PMID]

[20] Mihaylova V, Müller JS, Vilchez JJ, Salih MA, Kabiraj MM, D’amico $\mathrm{A}$, et al. Clinical and molecular genetic findings in COLQ-mutant congenital myasthenic syndromes. Brain. 2008; 131(3):747-59. [DOI:10.1093/brain/awm325] [PMID]

[21] Bestue-Cardiel M, de Cabezón-Alvarez AS, Capablo-Liesa J, López-Pisón J, Pe-a-Segura J, Martin-Martinez J, et al. Congenital endplate acetylcholinesterase deficiency responsive to ephedrine. Neurology. 2005; 65(1):144-6. [DOI:10.1212/01. wnl.0000167132.35865.31] [PMID]

[22] Yeung WL, Lam CW, Ng PC. Intra-familial variation in clinical manifestations and response to ephedrine in siblings with congenital myasthenic syndrome caused by novel COLQ mutations. Developmental Medicine \& Child Neurology. 2010; 52(10):e243e4. [DOI:10.1111/j.1469-8749.2010.03663.x] [PMID]

[23] Rinz CJ, Levine J, Minor KM, Humphries HD, Lara R, Starr-Moss AN, et al. A COLQ missense mutation in Labrador Retrievers having congenital myasthenic syndrome. PloS one. 2014; 9(8):e106425. [DOI:10.1371/journal.pone.0106425] [PMID] [PMCID]

[24] Zenker M, Aigner T, Wendler $O$, Tralau T, Müntefering $H$, Fensk $R$, et al. Human laminin $\beta 2$ deficiency causes congenital nephrosis with mesangial sclerosis and distinct eye abnormalities. Human Molecular Genetics. 2004; 13(21):2625-32. [DOI:10.1093/hmg/ ddh284] [PMID]

[25] Zemrani B, Cachat F, Bonny O, Giannoni E, Durig J, Fellmann F, et al. A novel LAMB2 gene mutation associated with a severe phenotype in a neonate with Pierson syndrome. European Journal of Medical Research. 2016; 21(1):19. [DOI:10.1186/s40001-0160215-z] [PMID] [PMCID]

[26] Ohno K, Quiram PA, Milone M, Wang H-L, Harper MC, Ned Pruitt J, et al. Congenital myasthenic syndromes due to heteroal- 
lelic nonsense/missense mutations in the acetylcholine receptor $\varepsilon$ subunit gene: Identification and functional characterization of six new mutations. Human Molecular Genetics. 1997; 6(5):753-66. [DOI:10.1093/hmg/6.5.753] [PMID]

[27] Rinz CJ, Lennon VA, James F, Thoreson JB, Tsai KL, Starr-Moss AN, et al. A CHRNE frameshift mutation causes congenital myasthenic syndrome in young Jack Russell Terriers. Neuromuscular Disorders. 2015; 25(12):921-7. [DOI:10.1016/j.nmd.2015.09.005] [PMID]

[28] Kraner S, Burgunder JM, Rösler K, Steinlein O, Sieb J. Congenital myasthenic syndrome due to heteroallelic nonsense/missense mutations in the acetylcholine receptor epsilon subunit gene. European Journal of Neurology. 2002; 9(6):694-5. [DOI:10.1046/ j.1468-1331.2002.00447_7.x] [PMID]

[29] Ohno K, Hutchinson DO, Milone M, Brengman JM, Bouzat C Sine SM, et al. Congenital myasthenic syndrome caused by prolonged acetylcholine receptor channel openings due to a mutation in the M2 domain of the epsilon subunit. Proceedings of the National Academy of Sciences. 1995; 92(3):758-62. [DOI:10.1073/ pnas.92.3.758]

[30] Croxen R, Newland C, Beeson D, Oosterhuis H, Chauplannaz G Vincent $A$, et al. Mutations in different functional domains of the human muscle acetylcholine receptor $\alpha$ subunit in patients with the slow-channel congenital myasthenic syndrome. Human Molecular Genetics. 1997; 6(5):767-74. [DOI:10.1093/hmg/6.5.767] [PMID]

[31] Shen XM, Brengman JM, Edvardson S, Sine SM, Engel AG. Highly fatal fast-channel syndrome caused by AChR -subunit mutation at the agonist binding site. Neurology. 2012; 79(5):449-54. [DOI:10.1212/WNL.0b013e31825b5bda] [PMID] [PMCID]

[32] Engel AG, Walls TJ, Nagel A, Uchitel O. Newly recognized congenital myasthenic syndromes: I. Congenital paucity of synaptic vesicles and reduced quantal release: I. Congenital paucity of synaptic vesicles and reduced quantal release, II. High-conductance fast-channel syndrome, III. Abnormal Acetylcholine Receptor (AChR) interaction with acetylcholine, IV. AChR deficiency and short channel-open time. Progress in Brain Research. 1990; 84:125-37. [DOI:10.1016/S0079-6123(08)60896-1]

[33] Fattahi Z, Kahrizi K, Nafissi S, Fadaee M, Abedini SS, Kariminejad A et al. Report of a patient with limb-girdle muscular dystrophy, ptosis and ophthalmoparesis caused by plectinopathy. Archives of Iranian Medicine. 2015; 18(1):60-4. [DOI: 0151801/AIM.0014] [PMID]

[34] Selcen D, Juel V, Hobson-Webb L, Smith E, Stickler D, Bite A, et al. Myasthenic syndrome caused by plectinopathy. Neurology. 2011; 76(4):327-36. [DOI:10.1212/WNL.0b013e31820882bd] [PMID] [PMCID]

[35] Maselli R, Arredondo J, Cagney O, Mozaffar T, Skinner S, Yousif $S$, et al. Congenital myasthenic syndrome associated with epidermolysis bullosa caused by homozygous mutations in PLEC1 and CHRNE. Clinical Genetics. 2011; 80(5):444-51. [DOI:10.1111/ j.1399-0004.2010.01602.x] [PMID]

[36] Régal L, Shen XM, Selcen D, Verhille C, Meulemans S, Creemers JW, et al. PREPL deficiency with or without cystinuria causes a novel myasthenic syndrome. Neurology. 2014; 82(14):1254-60. [DOI:10.1212/WNL.0000000000000295] [PMID] [PMCID]

[37] Jaeken J, Martens K, François I, Eyskens F, Lecointre C, Derua $R$, et al. Deletion of PREPL, a gene encoding a putative serine oligopeptidase, in patients with hypotonia-cystinuria syndrome.
The American Journal of Human Genetics. 2006; 78(1):38-51. [DOI:10.1086/498852] [PMID] [PMCID]

[38] Natera-de Benito D, Bestue M, Vilchez J, Evangelista T, Töpf A, Garcia-Ribes A, et al. Long-term follow-up in patients with congenital myasthenic syndrome due to RAPSN mutations. Neuromuscular Disorders. 2016; 26(2):153-9. [DOI:10.1016/j. nmd.2015.10.013] [PMID]

[39] Milone M, Shen X, Selcen D, Ohno K, Brengman J, lannaccone S, et al. Myasthenic syndrome due to defects in rapsyn Clinical and molecular findings in 39 patients. Neurology. 2009;73(3):228-35. [DOI:10.1212/WNL.0b013e3181ae7cbc] [PMID] [PMCID]

[40] Visser AC, Laughlin RS, Litchy WJ, Benarroch EE, Milone M. Rapsyn congenital myasthenic syndrome worsened by fluoxetine. Muscle \& Nerve. 2017; 55(1):131-5. [DOI:10.1002/mus.25244] [PMID]

[41] Tsujino A, Maertens C, Ohno K, Shen X-M, Fukuda T, Harper CM et al. Myasthenic syndrome caused by mutation of the SCN4A sodium channel. Proceedings of the National Academy of Sciences. 2003; 100(12):7377-82. [DOI:10.1073/pnas.1230273100] [PMID] [PMCID]

[42] Wu F, Mi W, Fu Y, Struyk A, Cannon SC. Mice with an NaV1. 4 sodium channel null allele have latent myasthenia, without susceptibility to periodic paralysis. Brain. 2016; 139(6):1688-99. [DOI:10.1093/brain/aww070] [PMID] [PMCID]

[43] Arnold WD, Feldman DH, Ramirez S, He L, Kassar D, Quick A et al. Defective fast inactivation recovery of Nav1. 4 in congenita myasthenic syndrome. Annals of Neurology. 2015; 77(5):840-50. [DOI:10.1002/ana.24389] [PMID] [PMCID]

[44] Huzé C, Bauché S, Richard P, Chevessier F, Goillot E, Gaudon K, et al. Identification of an agrin mutation that causes congenital myasthenia and affects synapse function. The American Journal of Human Genetics. 2009; 85(2):155-67. [DOI:10.1016/j. ajhg.2009.06.015] [PMID] [PMCID]

[45] Karakaya M, Ceyhan-Birsoy O, Beggs AH, Topaloglu H. A Novel Missense Variant in the AGRN Gene; congenital myasthenic syndrome presenting with head drop. Journal of Clinical Neuromuscular Disease. 2017; 18(3):147. [DOI:10.1097/ CND.0000000000000132] [PMID] [PMCID]

[46] Luan X, Tian W, Cao L. Limb-girdle congenital myasthenic syndrome in a Chinese family with novel mutations in MUSK gene and literature review. Clinical Neurology and Neurosurgery. 2016; 150:41-5. [DOI:10.1016/j.clineuro.2016.08.021] [PMID]

[47] Giarrana ML, Joset P, Sticht H, Robb S, Steindl K, Rauch A, et al. A severe congenital myasthenic syndrome with "dropped head" caused by novel MUSK mutations. Muscle \& Nerve. 2015; 52(4):668-73. [DOI:10.1002/mus.24687] [PMID]

[48] Ohkawara B, Cabrera-Serrano M, Nakata T, Milone M, Asai N, Ito $\mathrm{K}$, et al. LRP4 third $\beta$-propeller domain mutations cause novel congenital myasthenia by compromising agrin-mediated MUSK signaling in a position-specific manner. Human Molecular Genetics. 2013; 23(7):1856-68. [DOI:10.1093/hmg/ddt578] [PMID] [PMCID]

[49] Selcen D, Ohkawara B, Shen XM, McEvoy K, Ohno K, Engel AG. Impaired synaptic development, maintenance, and neuromuscular transmission in LRP4-related myasthenia. JAMA Neurology 2015; 72(8):889-96. [DOI:10.1001/jamaneurol.2015.0853] [PMID] [PMCID]

[50] Eguchi T, Tezuka T, Miyoshi S, Yamanashi Y. Postnatal knockdown of dok-7 gene expression in mice causes structural defects in neu- 
romuscular synapses and myasthenic pathology. Genes to Cells. 2016; 21(6):670-6. [DOI:10.1111/gtc.12370] [PMID]

[51] Azuma Y, Töpf A, Evangelista T, Lorenzoni PJ, Roos A, Viana P, et al. Intragenic DOK7 deletion detected by whole-genome sequencing in congenital myasthenic syndromes. Neurology Genetics. 2017; 3(3):e152. [DOI:10.1212/NXG.0000000000000152] [PMID] [PMCID]

[52] Lorenzoni PJ, Scola RH, Kay CS, Filla L, Miranda AP, Pinheiro JM, et al. Salbutamol therapy in congenital myasthenic syndrome due to DOK7 mutation. Journal of the Neurological Sciences. 2013; 331(1):155-7. [DOI:10.1016/j.jns.2013.05.017] [PMID]

[53] Kvist AP, Latvanlehto A, Sund M, Eklund L, Väisänen T, Hägg P et al. Lack of cytosolic and transmembrane domains of type XIII collagen results in progressive myopathy. The American Journal of Pathology. 2001; 159(4):1581-92. [DOI:10.1016/S00029440(10)62542-4]

[54] Logan CV, Cossins J, Cruz PMR, Parry DA, Maxwell S, MartínezMartínez $P$, et al. Congenital myasthenic syndrome type 19 is caused by mutations in COL13A1, encoding the atypical non-fibrillar collagen type XIII $\alpha 1$ chain. The American Journal of Human Genetics. 2015; 97(6):878-85. [DOI:10.1016/j.ajhg.2015.10.017] [PMID] [PMCID]

[55] Monies DM, Al-Hindi HN, Al-Muhaizea MA, Jaroudi DJ, AlYounes B, Naim EA, et al. Clinical and pathological heterogeneity of a congenital disorder of glycosylation manifesting as a myasthenic/myopathic syndrome. Neuromuscular Disorders. 2014; 24(4):353-9. [DOI:10.1016/j.nmd.2013.12.010] [PMID]

[56] Maselli R, Arredondo J, Nguyen J, Lara M, Ng F, Ngo M, et al. Exome sequencing detection of two untranslated GFPT1 mutations in a family with limb-girdle myasthenia. Clinical Genetics. 2014; 85(2):166-71. [DOI:10.1111/cge.12118] [PMID]

[57] Bauché S, Vellieux G, Sternberg D, Fontenille M-J, De Bruyckere E, Davoine C-S, et al. Mutations in GFPT1-related congenital myasthenic syndromes are associated with synaptic morphological defects and underlie a tubular aggregate myopathy with synaptopathy. Journal of Neurology. 2017; 264(8):1791-803. [DOI:10.1007/ s00415-017-8569-x] [PMID]

[58] Selcen D, Shen XM, Brengman J, Li Y, Stans AA, Wieben E, et al. DPAGT1 myasthenia and myopathy Genetic, phenotypic, and expression studies. Neurology. 2014; 82(20):1822-30. [DOI:10.1212/ WNL.0000000000000435] [PMID] [PMCID]

[59] Ibá-ez-Micó S, Domingo JR, Pérez-Cerdá C, Ghandour-Fabre D. Congenital myasthenia and congenital disorders of glycosylation caused by mutations in the DPAGT1 gene. Neurologia. 2017; pii: S0213-4853(17)30215-3. [DOI:10.1016/j.nrl.2017.05.002] [PMID]

[60] Schorling DC, Rost S, Lefeber DJ, Brady L, Müller CR, Korinthenberg $R$, et al. Early and lethal neurodegeneration with myasthenic and myopathic features A new ALG14-CDG. Neurology. 2017; 89(7):657-64. [DOI:10.1212/WNL.0000000000004234] [PMID]

[61] Belaya K, Rodríguez Cruz PM, Liu WW, Maxwell S, McGowan S, Farrugia ME, et al. Mutations in GMPPB cause congenital myasthenic syndrome and bridge myasthenic disorders with dystroglycanopathies. Brain. 2015; 138(9):2493-504. [DOI:10.1093/brain/ awv185] [PMID] [PMCID] 
